\title{
Research Paper: Knowledge and Attitude of Midwives and Obstetricians Towards Therapeutic Abortion Law and Its Ethical Pitfalls
}

\author{
Shabnam Bazmi' ${ }^{1}$, Mehrzad Kiani' ${ }^{1}$, Mahdieh Saidi² $^{\text {Q }}$, Forouzan Akrami $^{3^{*}}$
}

1. Department of Medical Ethics, School of Traditional Medicine, Shahid Beheshti University of Medical Sciences, Tehran, Iran 2. Mental Health Research Center, Psychosocial Health Research Institue, Iran University of Medical Sciences, Tehran, Iran.

3. Medical Ethics and Law Research Center, Shahid Beheshti University of Medical Sciences, Tehran, Iran.

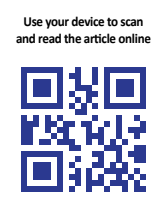

Citation: Bazmi S, Kiani M, Saidi M, Akrami F. Knowledge and Attitude of Midwives and Obstetricians Towards Therapeutic Abortion Law and Its Ethical Pitfalls. International Journal of Medical Toxicology and Forensic Medicine. 2021; 11(1):31958. https://doi.org/10.32598/ijmtfm.v11i.31958

https://doi.org/10.32598/ijmtfm.v11i.31958

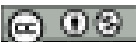

Article info:

Received: 25 Aug 2020

First Revision: 31 Aug 2020

Accepted: 29 Sep 2020

Published: 12 Apr 2021

\section{Keywords:}

Professional ethics, Abortion, Law, Midwives, Obstetricians

\section{ABSTRACT}

Background: Despite the implementation of a safe motherhood program in many countries, unsafe abortion continues to be a matter of reproductive health. Thus, urgent efforts to make abortion legal and safe have been recommended in developing countries. The present study was done to determine the knowledge of midwives and obstetricians about the therapeutic abortion law as well as their attitude about the ethical pitfalls.

Methods: In this descriptive knowledge and attitude study, a researcher-made questionnaire was used to gather data, after estimating the appropriate Cronbach's Alpha coefficient. A total of 162 midwives and obstetricians working in public and private medical centers affiliated to Shahid Beheshti University of Medical Sciences in 2018 were included in the study by convenience sampling method.

Results: According to the results, $9.3 \%$ of participants had a low level, $72.8 \%$ had a moderate level, and only $17.9 \%$ had a good level of knowledge. The total mean score of knowledge was $7.17 \pm 1.7$. The mean score of knowledge in the group of obstetricians $(7.60 \pm 1.74)$ was significantly higher than midwives $(6.94 \pm 1.54),(\mathrm{t}=2.29, \mathrm{P}=0.024)$. There was a significant correlation between participants' age and their knowledge ( $\mathrm{r}=0.912, \mathrm{P}=0.001)$. Also, $47.53 \%$ of the participants believed that the therapeutic abortion law has some pitfalls. The most frequent attitude was about the restriction of the therapeutic law up to 19 weeks for fetal indications.

Conclusion: The level of participants' knowledge was low to moderate. The findings indicated the need for training the professional standards related to prenatal genetic screening and therapeutic abortion.

* Corresponding Author:

Forouzan Akrami, MPH, PhD.

Address: Medical Ethics and Law Research Center, Shahid Beheshti University of Medical Sciences, Tehran, Iran.

Tel: +98 (912) 5173894

E-mail:froozan_akrami@yahoo.com 


\section{Background}

aving knowledge about the ethical and legal standards is the first step for H moral practice and professional protection against the law. For the observance of professional ethics, medical practitioners should be informed and act according to the professional code of ethics as well as regulations. Determining the mismatch between regulations and their enforcement and awareness about changes in the related regulations in favor of patients' interest, especially those who are vulnerable, is very important [1].

Despite the implementation of a safe motherhood program in many countries, unsafe abortion continues to be a matter of reproductive health, which has always been associated with many ethical and legal challenges. Also, $8 \%-11 \%$ of global maternal deaths are due to unsafe abortions and annually, about 22 million women have an unsafe abortion worldwide, the most of which occurs in the developing world where there are most restrictive access policies and social determinants that affect access to the safe services [2]. Thus, urgent efforts to make abortion legal and safe are recommended in developing countries in order to improve women's health and wellbeing [3].

Given the differences between communities in religious beliefs and cultural context, legal abortion is carried out in different countries through different laws. In some countries, such as Nepal, abortion is allowed before 12 weeks of gestation without any indication and before 18 weeks of gestation if the mother's life is threatened or the fetus has an incompatible anomaly with life or in the case of rape. But in India, individual abortions is allowed beyond the 20-week upper limit [4]. In Iran, the only legally permitted type of abortion is therapeutic abortion when the mother's life is threatened or when there is an incompatible congenital anomaly with life and/or serious fetal disease; however, it is not allowed after 19 weeks of pregnancy [5].

The right to abortion and its decriminalization to make abortion safe [6] has been discussed, but regarding various cultural contexts of different countries and also medical consequences and psycho-somatic harms of abortion, the principles of utility and no-harm principle in Islamic jurisprudence requires maximizing benefits by minimizing harms in health policy-making. Thus, some decision-makers prefer protecting the right to regulate birth intervals and recommend the policy of access to contraception for all women, especially women with low socio-economic classes and those with a history of the birth of a newborn with genetic diseases, and also making law according to religious teachings in order to reduce unwanted pregnancies and unsafe abortions, instead of full decriminalization of the abortion [7]. Midwives as frontline health care providers have a key role in informing and preparing the women to make the right decisions that can save their lives. However, lack of enough knowledge about professional codes of ethics and regulations will lead to providing inappropriate information and care to women, which can harm them. A study in Jamaica on physicians, nurses, and midwives showed that more than $80 \%$ of them believed that there should be legal abortion in certain cases and the medical staff and doctors should be ready to provide information to women with the necessary services [8]. A study in Argentina has shown that after changing the law of abortion in this country, due to insufficient knowledge of health care providers about the reforms, people were exposed to risk [9]. On the other hand, the findings of a systematic literature review showed also that women's knowledge about abortion law and legal restrictions was limited and the promotion of their knowledge about related regulations is necessary [10].

In many cases, due to the lack of sufficient knowledge of the professionals, many cases are authorized to abort leading to clandestine abortions and their complications. Based on the latest changes in the therapeutic abortion law in Iran in 2005, permitted abortion is considered in cases where the risk of maternal death is probable and also abnormalities and severe fetal diseases that result in inevitable intrauterine death or the death of infant immediately after birth. However, considering the limited number of authorized cases of abortion and its prohibition in cases, such as unwanted pregnancy and illicit sexual relation, there are still many cases of abortioninduced complications, such as maternal bleeding, sepsis, and death [11].

Illegal abortions are usually carried out by the individual or non-professionals and by offending doctors or midwives, and often via unsafe methods. A study in India has shown that $8 \%$ of the annual deaths of women are due to unauthorized and unsafe abortions and one of the reasons for such abortions is inadequate knowledge about abortion law and its regulations by caregivers [12]. On the other hand, to ensure public compliance with the law, the question that must be answered is whether the law is consciously formulated and adopted in accordance with ethical principles and rules. Hence, assessing the knowledge level of medical staff about au- 
thorized abortion cases and related administrative laws along with eliminating ethical pitfalls can help us enforce regulations and reduce the number of unsafe abortion cases and medical staff offenses, and finally promote community health. Moreover, the survey of field users and utilization of the results should be considered for informed decision-making so that the regulations have an executive guarantee. Objectives: the present study was done to assess the knowledge level of midwives and obstetricians working in public and private hospitals affiliated to Shahid Beheshti University of Medical Sciences (SBMU), Tehran, Iran, about the process and indications of administrative abortion law as well as their attitude about its ethical pitfalls.

\section{Materials and Methods}

\section{Study participants}

This descriptive cross-sectional study was carried out on 162 obstetricians and midwives working in public and private hospitals affiliated to SBUM in 2018. A total of 170 midwives (women who qualified to provide reproductive health care, such as prenatal care and vaginal delivery) and obstetricians (women who qualified to do cesarean section and other obstetric and gynecologic examinations and surgeries) were recruited in the study. The sample size was estimated to be 132 persons, based on the standard deviation reported by similar studies with an alpha of 0.05 and the maximum acceptable error of 1.5 [13].

$$
N=\left(\frac{Z \times S D}{d}\right)^{2}=\left(\frac{1.96 \times 8.8}{d}\right)^{2}=132 \text { cases }
$$

\section{Data collection and analysis}

Data were collected through a three-part researchermade questionnaire in an anonymous and self-report manner, which was made based on the content of therapeutic abortion administrative law. The first part was about demographic characteristics of the participants, the second part consisted of 8 close-end questions with 4-option answers to assess the knowledge of the participants about the process of therapeutic abortion, and 8 close-end questions with 2-option answers (correct or incorrect) to assess the knowledge of the participants about the indications of therapeutic abortion. The third part was one open-end question used to assess the participants' attitude about the ethical pitfalls of abortion law.

Then, the research questionnaire was developed and reviewed by 10 specialists in medical ethics and forensic medicine in terms of literary structure, clarity of the questions, and coverage of investigated items to determine the content validity. Content Validity Index (CVI) of $90 \%$ and Cronbach's Alpha coefficient of 0.80 were obtained for the scale.

After expressing goals and obtaining verbal consent of the participants, the questionnaires were distributed through convenience sampling method among obstetricians and midwives by one of the researchers and collected $30 \mathrm{~min}$ after distribution. For evaluating responses, the score of 1 was assigned to the correct choices and 0 was considered for the wrong or unanswered options (total score=15). After summing the scores, the percentage of participants' awareness was classified into three levels of good $(>70 \%)$, moderate $(35-70 \%)$ and weak $(<35 \%)$.

Data were analyzed by SPSS software version 20 . The t-test and one-way Analysis of Variance (ANOVA) were used at the significance level of $\mathrm{P}<0.05$ for data analysis.

\section{Results}

Of 170 midwives and obstetricians, 162 cases filled the research questionnaire (95.3\%). All participants were women with a mean age of $42.8 \pm 8.2$ years and $53.8 \%$ of them were obstetricians and $46.2 \%$ were midwives. Also, $54.7 \%$ of the participants were working in the private sector and $46.3 \%$ of them were working in the public sector (Table 1).

The total mean knowledge score of the participants was $7.17 \pm 1.7$ (minimum: 3 and maximum: 12.07) from the reference score 15 . According to the results, $9.3 \%$ of the participants had a low level, $72.8 \%$ had a moderate level, and only $17.9 \%$ had a good level of knowledge. Also, $95.6 \%$ of the participants were not informed that in the case of maternal or fetal indication, the mother's consent is enough to permit abortion. Regarding the indications of legal abortion, $77.8 \%$ of participants thought that abortion is permitted if there is any malformation in the fetus and 75\% did not know that in the case of fetal disease, diagnosis of the mother's difficulty and hardship is an important criterion for permission to abort (Table 2).

The mean score of knowledge in the group of obstetricians was significantly higher than midwives $(\mathrm{t}=2.29$, $\mathrm{P}=0.024)$. However, there was no significant difference in the mean knowledge score among the graduates of various levels of midwifery $(\mathrm{F}=1.39, \mathrm{P}=0.134)$. The mean of knowledge of single and married individuals $(\mathrm{t}=0.165, \mathrm{P}=0.869)$, faculty members and non-faculty members $(\mathrm{t}=1, \mathrm{P}=0.318)$, those working in different set- 
Table 1. Frequency of demographic characteristics of the participants

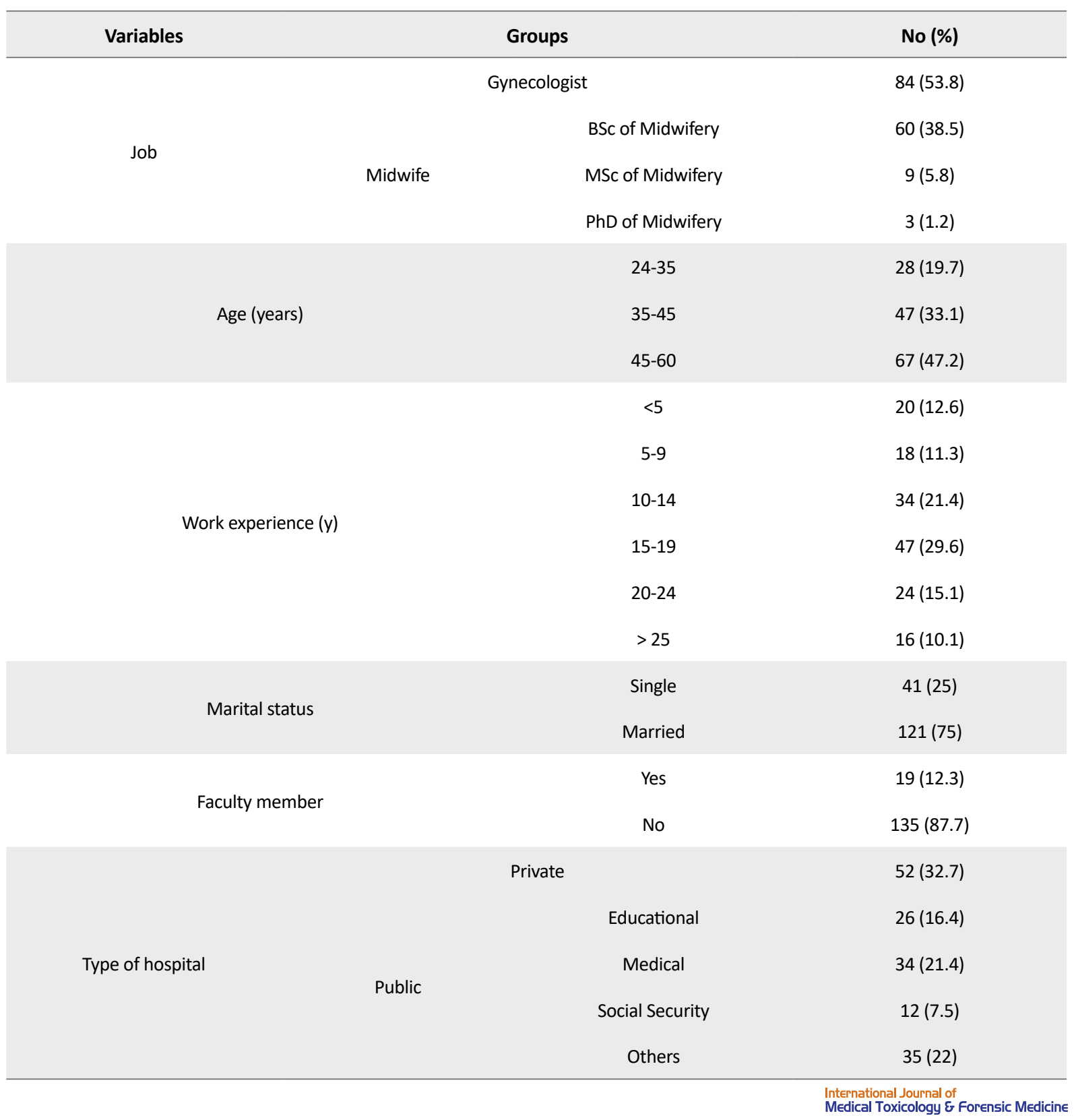

tings $(\mathrm{F}=0.87, \mathrm{P}=0.483)$, and those with different work experience $(\mathrm{F}=0.89, \mathrm{P}=0.489)$ did not have a significant difference (Table 3). However, there was a significant difference in mean knowledge among different age groups $(\mathrm{F}=3.03, \mathrm{P}=0.052)$; the higher mean knowledge level was related to the 35-45 years group and the lowest level was related to the 45-60 years group (Table 4 ). The analysis of the answers to the open-end question showed that $47.53 \%$ of participants believed the therapeutic abortion law has some ethical pitfalls (Table 5).

\section{Discussion}

Our findings showed that participants' knowledge about the process and indications of administrative abortion law was low to moderate and the mean score of knowledge of obstetricians was significantly higher than midwives. A study conducted in Yazd City showed similar results [13]. Also, the midwives' knowledge and attitude toward abortion law were at a low to moderate level in Isfahan City [14]. Another study also showed that only $48.3 \%$ of Brazilian obstetricians had correct knowledge about abortion law [15]. Another study in Guatemala also showed a moderate level of knowledge among 
Table 2. Frequency of participants' knowledge about therapeutic abortion law

\begin{tabular}{|c|c|c|c|}
\hline \multirow[b]{2}{*}{ Field } & \multirow[b]{2}{*}{ Questions } & \multicolumn{2}{|r|}{ No. (\%) } \\
\hline & & Correct & $\begin{array}{l}\text { Incorrect or } \\
\text { Without Answer }\end{array}$ \\
\hline \multirow{8}{*}{ 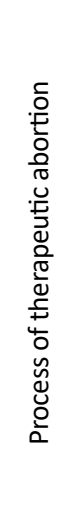 } & 1. What is the allowed time for therapeutic abortion? & $77(47.8)$ & $84(52.2)$ \\
\hline & 2. Who should be consented to therapeutic abortion? & $7(4.4)$ & $152(95.6)$ \\
\hline & 3. What is the first action after the pregnant woman's request for therapeutic abortion? & $74(46.2)$ & $86(53.8)$ \\
\hline & 4. What are the authorized cases in abortion laws? & $112(69.6)$ & $49(30.4)$ \\
\hline & $\begin{array}{l}\text { 5. How many diagnostic imaging tests are needed before a legal abortion for fetal indica- } \\
\text { tions? }\end{array}$ & $125(77.6)$ & $36(22.4)$ \\
\hline & $\begin{array}{l}\text { 6. How many diagnostic imaging tests required before a legal abortion for maternal indica- } \\
\text { tions? }\end{array}$ & $83(52.9)$ & $74(47.1)$ \\
\hline & 7. How many trusted experts should confirm the need for therapeutic abortion? & $45(29.2)$ & $109(70.8)$ \\
\hline & 8. The final confirmation of which legal reference is required for abortion? & $151(93.8)$ & $10(6.2)$ \\
\hline \multirow{7}{*}{ 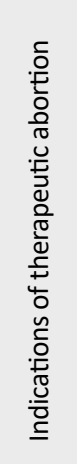 } & $\begin{array}{l}\text { 9. There is legal regulation for therapeutic abortion in our country in case of fetal or maternal } \\
\text { indications. }\end{array}$ & $124(79)$ & $33(21)$ \\
\hline & 10. Mother's Chronic diseases that become more severe with pregnancy. & $106(68.4)$ & $49(31.6)$ \\
\hline & 11. The disease of the mother threatens maternal life. & $156(96.9)$ & $5(3.1)$ \\
\hline & 12. Mother's disease is progressive and incurable. & $102(65)$ & $55(35)$ \\
\hline & 13. Fetal disease that causes mental retardation. & $42(26.9)$ & $114(73.1)$ \\
\hline & 14. Fetal disease that resulted in the birth of a malformed and defective newborn. & $35(22.2)$ & $123(77.8)$ \\
\hline & 15. Fetal disease that causes difficulty and hardship. & $38(24.4)$ & $118(75.6)$ \\
\hline
\end{tabular}

obstetricians about medical abortion law [16]. Because midwives and obstetricians are the medical practitioners to whom most pregnant women refer for abortion, these results indicate the need to train them about abortion administrative law.

In our study, most participants were not informed that in the case of maternal or fetal indication, the mother's consent is enough to permit abortion. Moreover, most of them were not aware that in the case of fetal disease, diagnosis of the mother's difficulty and hardship is the major criterion for permission to abort, "thus, "respect for mother,s autonomy, not strict autonom" is a matter of distinguishing between the therapeutic abortion laws in our society with other secular societies.

Table 3. The mean knowledge based on job, marriage status, and being a faculty member

\begin{tabular}{clc}
\hline Study Groups & Mean \pm SD & Sig. \\
\hline Gynecologists & $7.60 \pm 1.74$ & $\mathrm{t}=2.29$ \\
Midwives & $6.93 \pm 1.54$ & $\mathrm{P}=0.024$ \\
Single & $7.37 \pm 1.61$ & $\mathrm{t}=0.16$ \\
Married & $7.31 \pm 1.76$ & $\mathrm{P}=0.87$ \\
Faculty member & $6.92 \pm 1.42$ & $\mathrm{t}=-1$ \\
Non-faculty member & $7.40 \pm 1.78$ & $\mathrm{P}=0.32$ \\
\hline
\end{tabular}


Table 4. Mean difference of knowledge between age groups (ANOVA)

\begin{tabular}{|c|c|c|c|c|c|}
\hline \multirow{2}{*}{ Age Groups (I) } & \multirow{2}{*}{ (J) } & \multirow{2}{*}{ Mean Difference \pm SE (I-J) } & \multirow{2}{*}{ Sig. } & \multicolumn{2}{|c|}{ 95\% Confidence Interval } \\
\hline & & & & Lower Bound & Upper Bound \\
\hline \multirow[t]{2}{*}{$24-35$} & $35-45$ & $0.50 \pm 0.41$ & 0.45 & -0.48 & 1.49 \\
\hline & $45-60$ & $-0.32 \pm 0.40$ & 0.70 & -1.25 & 0.62 \\
\hline \multirow[t]{2}{*}{$35-45$} & $24-35$ & $-0.50 \pm 0.41$ & 0.45 & -1.49 & 0.48 \\
\hline & $45-60$ & $-0.82 \pm 0.33^{*}$ & 0.04 & -1.61 & -0.02 \\
\hline \multirow[t]{2}{*}{$45-60$} & $24-35$ & $0.32 \pm 0.39$ & 0.70 & -0.62 & 1.25 \\
\hline & $35-45$ & $0.82 \pm 0.33^{*}$ & 0.04 & 0.02 & 1.61 \\
\hline
\end{tabular}

* The mean difference is significant at the 0.05 level.

Table 5. Frequency of participants' attitude toward pitfalls of therapeutic abortion law

\begin{tabular}{lc}
\hline \multicolumn{1}{c}{ Attitudes } & No (\%) \\
\hline Not considering fetal anomalies with late diagnosis and restriction of the law up to 19 weeks for fetal indications. & 21 (12.96) \\
\hline Not surveying the public reasons for illegal abortion and not considering the right of abortion for women & $17(10.49)$ \\
\hline Prolongation of the process of legal abortion and passing the deadline in some cases of prenatal screening & 13 (8.02) \\
\hline Lack of revision of the maternal and fetal indications of the legal abortion and clarification of them & 13 (8.02) \\
\hline Prohibition of therapeutic abortion law in illegitimate pregnancies, rape cases, and addicted and homeless mothers & 10 (6.17) \\
\hline Low awareness of the public and the lack of universal access to diagnostic technologies in all areas & 2 (1.22) \\
\hline
\end{tabular}

In the present study, the mean knowledge of participants was not significantly different among single and married cases, faculty and non-faculty members, those working in different workplaces, and cases with different work experiences. However, the mean knowledge level among different age groups was significantly different. In another study, there was a statistically significant difference between the mean knowledge with regard to the workplace of the midwives. The most important influencing factors on knowledge were the legal abortionrelated experience and workplace so that those working in the university were more aware and experienced [14]. It was also reported that obstetricians with fewer years of experience had low knowledge about legal and medical aspects of abortion [16]. Thus, increasing age is associated with more experiences about the complications of illegal and unsafe abortion, and subsequently required information about its rules. However, young and older age groups need to continue education courses.

As noted, about half of the participants believed that the administrative abortion law has some ethical pitfalls.
The highest frequency of the presented attitudes associated with fetal abnormalities suggests a low level of knowledge of the participants about the ethical and legal implications of prenatal genetic screening and how to deal with it. A qualitative study indicated that abortion following positive prenatal diagnostic tests and late abortion were more frequent ethical issues [17]. On the other hand, it is believed that increasing the range of authorized cases of fetal abnormalities for abortion, resulted in the stigmatization of some abnormalities, ethically. Because the only option after positive results for the genetic test is doing or not doing the abortion, and the purpose of these programs is to make autonomous reproductive decisions by women [18], holding related educational courses for health care practitioners is a gap in our health care system.

The lack of surveying the public reasons for illegal abortion and not considering the right of abortion for women was the second frequent item. The results of a Swedish study showed that the majority of midwives and obstetricians agreed to legislate abortion and make autonomous 
decisions by woman, and disagreed with using abortion as a contraception method, but they had less restrictive views similar to our results [19]. Thus, revising prenatal screening program for Down syndrome and developing a national protocol for fetal anomaly scan during pregnancy, standardizing the related genetics diagnostic tests, covering the costs by third party companies for universal access, and timely action according to standards of professional ethics are needed to reduce illegal and unsafe abortions. As mentioned in Islamic jurisprudence, in the case of fetal disease or anomaly, diagnosis of the mother's difficulty and hardship is a major criterion to allow the abortion; thus, given the social changes, surveying the public reasons for illegal and unsafe abortions and considering and respecting the right of abortion for women due to this criterion is suggested.

Moreover, informing and counseling, equitable access to screening services and other diagnostic procedures and technologies to reduce inequalities in health outcomes as an ethical goal of public health, and considering cases, such as a pregnancy resulted from rape due to mental harm, are the items, which should be considered by policy-makers for informed decision-making through ethical tradeoffs. Bazmi et al. in their comparative study on therapeutic abortion permissions in the central clinical department of the Legal Medicine Organization in Tehran before and after the approval of the law on abortion in Iran concluded that the abortion law needs to be revised by different authorities and governmental and judicial organizations [20]. Abbasi et al. also recommended the ethical evaluation of the legal system in the study on the decriminalization process of abortion and reminded the role of the public and demand of professionals in starting this process in Iran's legal system [21].

The exploration of the knowledge and attitude of both obstetricians and midwives about therapeutic abortion law as well as the ethical pitfalls were the strengths of this study in comparison with similar studies. Among the limitations of this study was selecting the sample from those working in medical centers affiliated with SBUM. Thus, the extended and in-depth survey of the attitude and viewpoint of other medical staff working in different medical settings, policy-makers, and also the public opinion is recommended.

\section{Conclusions}

The low to the moderate knowledge level of the most of participants indicates the need to hold educational courses on ethical and legal issues related to prenatal genetic screening as well as administrative abortion law.

\section{Ethical Considerations}

\section{Compliance with ethical guidelines}

This research was approved by Research Ethics Review Committee of the Shahid Beheshti University of Medical Sciences. Verbal consent were obtained from the subjects (Code: SBMU.REC.1392.580).

\section{Funding}

This research proposal was adopted and funded by Medical Ethics and Law Research Center, Shahid Beheshti University of Medical Sciences, Tehran.

\section{Author's contributions}

Conceptualization, Funding Acquisition and Resources, and Methodology: Shabnam Bazmi and Mehrzad Kiani; Investigation, Writing - original draft, and Data collection: Shabnam Bazmi, Mahdieh Saidi, and Forouzan Akrami; Data analysis: Forouzan Akrami; Writing - Review \& Editing: All authors; Supervision: Shabnam Bazmi, Mehrzad Kiani, and Forouzan Akrami.

\section{Conflict of interest}

The authors declared no conflict of interest.

\section{References}

[1] Fathalla MF. Human rights aspects of safe motherhood. Best Pract Res Clin Obstet Gynaecol. 2006; 20(3):409-19. [DOI:10.1016/j.bpobgyn.2005.11.004] [PMID]

[2] Shah IH, Åhman E. Unsafe abortion differentials in 2008 by age and developing country region: High burden among young women. Reprod Health Matters. 2012; 20(39):169-73. [DOI:10.1016/S0968-8080(12)39598-0]

[3] Bartlett LA, Berg CJ, Shulman HB, Zane SB, Green CA, Whitehead S, et al. Risk factors for legal induced abortionrelated mortality in the United States. Obstet Gynecol. 2004; 103(4):729-37. [DOI:10.1097/01.AOG.0000116260.81570.60] [PMID]

[4] Samandari G, Wolf M, Basnett I, Hyman A, Andersen K. Implementation of legal abortion in Nepal: A model for rapid scale-up of high-quality care. Reprod Health. 2012; 9:7. [DOI:10.1186/1742-4755-9-7] [PMID] [PMCID]

[5] Erfani A. Levels, trends and correlates of abortion in Tehran, Iran: 2009-2014. Int Perspect Sex Reprod Health. 2016; 42(2):93-101. [DOI:10.1363/42e1316] [PMID]

[6] Berer M, Hoggart L. Progress toward decriminalization of abortion and universal access to safe abortions: National 
trends and strategies. Health Hum Rights. 2019; 21(2):79-83. [PMID] [PMCID]

[7] Hourieh SM, Abolghasem P, Feizollah A. Knowledge and attitudes of a number of Iranian policy- makers towards abortion. J Reprod Infertil. 2010; 11(3):189-95. [PMID] [PMCID]

[8] Smith KA, Johnson RL. Medical opinion on abortion in Jamaica: A national Delphi survey of physician, nurses, and midwives. Stud Fam Plann. 1976; 7(12):334-9. [DOI:10.2307/1965964] [PMID]

[9] Ramos S, Romero M, Ramón Michel A. Health care providers' opinions on abortion: A study for the implementation of the legal abortion public policy in the Province of Santa Fe, Argentina. Reprod Health. 2014; 11:72. [DOI:10.1186/17424755-11-72] [PMID] [PMCID]

[10] Assifi AR, Berger B, Tunçalp Ö, Khosla R, Ganatra B. Women's awareness and knowledge of abortion laws: A systematic review. PLoS One. 2016; 24;11(3):e0152224. [DOI:10.1371/ journal.pone.0152224] [PMID] [PMCID]

[11] Mirzamoradi M, Saleh M, Jamali M, Bakhtiyari M, Pooransari P, Saleh Gargari S. Factors related to unwanted pregnancies and abortion in the northern district of the city of Tehran, Iran. Women Health. 2018; 58(6):714-28. [DOI:10.1080/036302 42.2017.1342738] [PMID]

[12] Sjöström S, Essén B, Gemzell-Danielsson K, Klingberg-Allvin $M$. Medical students are afraid to include abortion in their future practices: In-depth interviews in Maharastra, India. BMC Med Educ. 2016; 16:8. [DOI:10.1186/s12909-016-0532-5] [PMID] [PMCID]

[13] Ghadipasha M, Bashardoost N, Ghodoosi A, Samadirad B, Nikian Y, Roohparvar R. [Knowledge level of gynecologists and midwives of Yazd concerning rules and regulations of therapeutic abortion (legal) and criminal abortion (Persian)]. J Shahid Sadoughi Univ Med Sci. 2011; 19(2):141-7. https:// www.sid.ir/fa/journal/ViewPaper.aspx?ID=151078

[14] Afhami N, Bahadoran P, Taleghani HR, Nekuei N. The knowledge and attitudes of midwives regarding legal and religious commandments on induced abortion and their relationship with some demographic characteristics. Iran J Nurs Midwifery Res. 2016; 21(2):177-82. [DOI:10.4103/17359066.178244] [PMID] [PMCID]

[15] Goldman LA, García SG, Díaz J, Yam EA. Brazilian obstetrician-gynecologists and abortion: A survey of knowledge, opinions and practices. Reprod Health. 2005; 2:10. [DOI:10.1186/1742-4755-2-10] [PMID] [PMCID]

[16] Kestler E. Obstetrician-Gynecologists' knowledge of and attitudes toward medical abortion in Guatemala. Int J Gynaecol Obstet. 2012; 116(2):120-3. [DOI:10.1016/j.ijgo.2011.09.015] [PMID]

[17] Oelhafen S, Monteverde S, Cignacco E. Exploring moral problems and moral competences in midwifery: A qualitative study. Nurs Ethics. 2019; 26(5):1373-86. [DOI:10.1177/0969733018761174] [PMID]

[18] Stapleton G. Qualifying choice: Ethical reflection on the scope of prenatal screening. Med Health Care Philos. 2017; 20(2):195205. [DOI:10.1007/s11019-016-9725-2] [PMID] [PMCID]

[19] Hammarstedt M, Jacobsson L, Wulff M, Lalos A. Views of midwives and gynecologists on legal abortion-a populationbased study. Acta Obstet Gynecol Scand. 2005; 84(1):58-64. [DOI:10.1111/j.0001-6349.2005.00695.x] [PMID]
[20] Bazmi S, Behnoush B, Kiani M, Bazmi E. [Comparative study of therapeutic abortion permissions in central clinical department of Tehran Legal Medicine Organization before and after approval of law on abortion in Iran (Persian)]. Iran J of Pediatr. 2008; 18(4):315-22. https://www.sid.ir/en/journal/ViewPaper.aspx?id=124878

[21] Abbasi M, Gooshki ES, Allahbedashti N. Abortion in Iranian legal system. Iran J Allergy Asthma Immunol. 2014; 13(1):7184. https://ijaai.tums.ac.ir/index.php/ijaai/article/view/473 
Contribution Details (to be ticked marked as applicable):

\section{Contributor 1 Contributor 2 Contributor 3 Contributor 4}

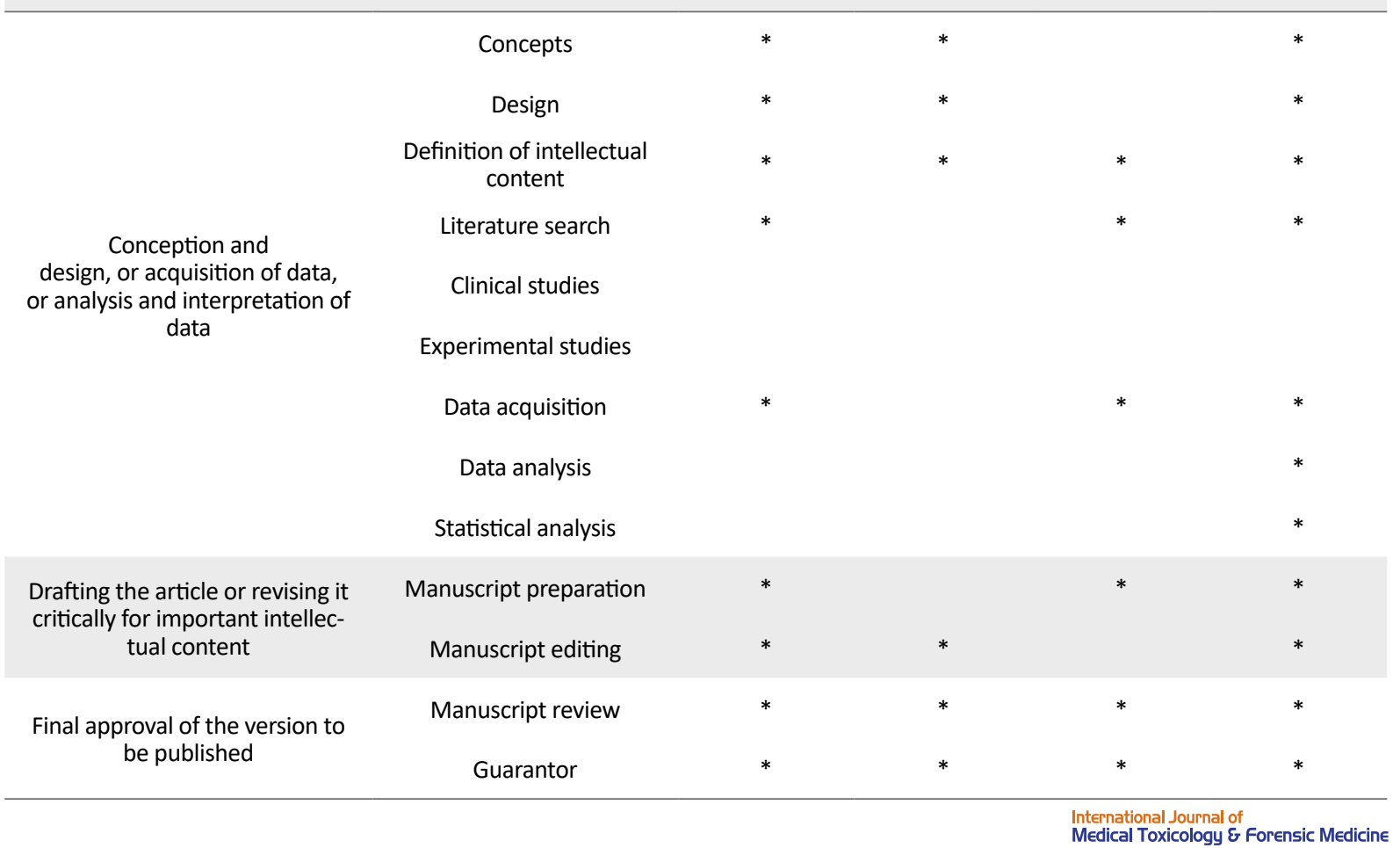

